\title{
A concepção bergsoniana do tempo
}

\author{
Frederic Worms \\ Université de Lille III
}

resumo Trata-se aqui de mostrar como a filosofia de Bergson decorre da constatação da passagem do tempo enquanto fato primordial e originário; nessa medida, as suas obras podem ser consideradas como diferentes tentativas de esclarecer tal experiência da temporalidade que, filosoficamente considerada, consiste na intuição da duração. Para isso, examina-se a forma pela qual o tratamento dado a problemas filosóficos distintos e discutidos em cada um de suas obras efetiva-se como meditação sobre o fato primitivo e seu esclarecimento progressivo. Em primeiro lugar, acompanhamos o percurso de dedução das principais características da duração, sucessão, conservação e ato, sublinhando algumas de suas conseqüências filosóficas. A seguir, examinamos a dimensão crítica da filosofia de Bergson pela análise do pensamento do instante, aquele que desfigura a experiência do tempo e origina a via equivocada da metafísica tradicional; nesseexame procuramos diferenciar tal pensamento da experiência da simultaneidade, que é constitutiva de nossa relação concreta com as coisas.

palavras-chave duração, sucessão, simultaneidade, criação, experiência, instante

Não se tratará aqui de estudar o lugar de uma questão geral numa filosofia singular entre outras, a saber, "a" questão do tempo na filosofia "de Bergson". É toda a sua filosofia, com efeito, que Bergson apresenta como decorrência, não da "questão" do tempo, mas da simples constatação da passagem do tempo, do simples fato de que o tempo passa. A radicalidade desse encontro proíbe-nos portanto de pressupor o que quer que seja no que concerne à história desse problema ou à interpretação dessa doutrina, e nos lega uma tarefa muito mais difícil:compreender

"La conception bergsonienne du temps", publicado em Philosophie, n54, p.73-91. Tradução de Débora Morato Pinto 


\section{0}

como uma filosofia inteira pode fundar-se sobre esse simples fato, testar em contrapartida tal filosofia em sua capacidade de esclarecer a integralidade dessa experiência, colocada como irredutível.

Se a tarefa tem algum interesse, é exatamente porque Bergson não se satisfez em constatar a passagem do tempo. Podemos indicar de imediato em quais direções essa constatação ou antes essa surpresa inicial parece ter engajado o filósofo: cada uma dessas direções é um problema que será preciso resolver primeiramente, na condição de, em seguida, reencontrar seu próprio ponto de origem de onde elas saíram.

"Constatar" que o tempo "passa" parece de início conduzir Bergson a uma dupla tese de realidade: não somente da realidade do tempo em si mesmo, apesar de sua passagem contínua, mas também, justamente porque sua desaparição parece imediatamente anular sua existência, a da consciencia ou do sujeito que se apercebe de tal passagem. Qual é o sentido desse duplo realismo, tão controverso, da duração e do espírito,qual é a ligação entre essas duas realidades? Tal seria a primeira questão a resolver. Mas se a passagem do tempo é a uma só vez uma evidência imediata e uma surpresa permanente, é também porque esse fato parece escapar incessantemente ao nosso conhecimento: Bergson parece conduzido, desde os seus primeiros passos filosóficos, a uma crítica de nosso conhecimento, não pelo fato de que este ultrapassa seu objeto, mas sim porque o perde, no caso do tempo real, e isso por razões constitutivas. Qual é então o sentido da crítica, igualmente tão discutida, por que impõe ela uma separação tão radical entre a realidade do tempo e o que seria uma certa idealidade do espaço, entre nosso ser e nosso conhecimento, até mesmo entre nosso espírito e nosso corpo, portanto entre duas regiões do próprio ser? Mas é preciso ir mais longe. Seria a simples "passagem" do tempo, em sua positividade e sua continuidade, suficiente para dar conta de nossa experiência do próprio tempo na sua diversidade, quer seja sob os três aspectos originários do presente, do passado e do futuro, quer sob a forma do tempo "do mundo", do movimento ou ainda da história? Esta é realmente a última questão a ser colocada: ela implica, para uma tal filosofia, reunir o que ela inicialmente separou, caso queira dar conta do "misto" que parece constituir a experiência "humana" do tempo. Mais que isso, a descoberta da duração e a crítica do espaço, para serem propriamente filosóficas, não podem ser exteriores, e devem se inscrever na relação de cada consciência singular consigo mesma. É certamente por isso que a surpresa sentida por Bergson se desdobra finalmente num afeto ou numa emoção, numa "alegria" que não é somente uma atitude subjetiva entre 
outras, entre as quais poder-se-ia escolher (tal como a tristeza ou a angústia), mas atesta o alcance intrinsecamente prático, numa vida singular, de toda "concepção" do "tempo" em geral.

Tais seriam as questões a resolver. Acaso caberia agora escolher entre os dois únicos métodos que parecem se oferecer para tanto, levando em conta a obra bergsoniana? De um lado, com efeito, esses três aspectos da "concepção bergsoniana do tempo" não podem ser reapreendidos, em sua unidade, a não ser através de cada um dos livros em que Bergson os colocou em ação para tratar de maneira autônoma de um problema determinado. De outro lado, se há efetivamente uma questão que possa e que deva ser tratada de modo sintético, através do conjunto da obra (cuja coerência ela possibilitaria, no mesmo golpe, apreciar melhor), é certamente a questão do tempo. O que está em jogo parece mesmo ultrapassar a mera questão de uma "evolução" da filosofia de Bergson: trata-se do acesso à própria unidade desse pensamento enquanto tal.

Mas talvez não seja necessário sacrificar um método pelo outro. A coerência desse pensamento do tempo é indissociável das etapas distintas de seu fazer-se, mesmo se impõe precisamente reencontrar a cada vez a "mesma" experiência ou antes a mesma "surpresa". Inversamente, não causará espanto se, no interior do percurso de conjunto, encontrarmos rupturas internas, as quais recobrem as unidades distintas de pensamento que são notadamente o Essai sur les données immédiates de la conscience,de 1889, Matièreet Mémoire, de 1896, e L'Évolution Créatrice, de 19072. Se foi preciso uma pluralidade irredutível de esforços para revelar o alcance daquilo que permanece um ponto de partida único, isto mesmo é duplamente revelador. Para começar, foi necessário, a cada vez, conciliar novamente os contrários, o tempo e o espaço, o ser e o conhecimento, ou aquilo que se poderia chamar o pensamento da imanênciae da diferença: o que nos impede de reduzir o pensamento de Bergson a um simples "realismo" do tempo ou a uma pura crítica da "inteligência". Mas tal pluralidade de livros remete também, para além de uma intuição inicial e de um sistema global, a uma diversidade aberta de problemas filosóficos e de regiões da experiência, que corresponderiam a outras dimensões de nossa relação com o mundo e com nós mesmos: todas se uniriam e se distinguiriam, se cruzariam, para cada um de nós, em certos pontos do tempo. Tal será talvez a dupla lição a se tirar de um estudo sobre a "concepção bergsoniana do tempo".

Mas é preciso inicialmente voltar para as etapas dessa concepção mesma. 
132

\section{Do decorrer do tempo à idéia de duração}

É preciso então tornar a partir da passagem ou do decorrer do tempo, para mostrar como Bergson pôde deduzir, desse simples fato, os principais aspectos do tempo em si, ou antes da duração, se a noção tradicional de "tempo" devia precisamente trair tais características primeiras. Mais ainda, dever-se-á mostrar como, a cada etapa de sua obra, Bergson retorna efetivamente a esse decorrer enquanto tal, aprofundando e renovando assim, diante de cada novo problema, as caraterísticas do tempo real. Dessa forma, mesmo se o presente contínuo da duração, tal como o apresentava o Essai de 1889, já abarcava, por princípio, a memória do passado e a criação do futuro, cada um desses aspectos fundamentais exigirá, para ser compreendido enquanto tal, uma retomada específica, e um retorno (imanente) à passagem do tempo em si.

Mas como se pode "deduzir" desse único fato a própria natureza do tempo em geral? Bergson realmente procedeu dessa maneira?

Pode ser, com efeito, que o caráter primitivo (e não constituível) da passagem do tempo não tenha aparecido a Bergson diretamente, mas de início apenas de maneira crítica. É o que ele evocará sempre, até o relato retrospectivo que abrirá sua última coletânea de ensaios, La Pensée et le mouvant, em 1934: "Nós ficamos muito impressionados ao ver como o tempo real $<\ldots>$ escapa à matemática. Sua essência sendo passar, nenhuma de suas partes permanece quando outra se apresenta..."(BERGSON, 1959, p.1254; grifo meu).

Mas se esta primeira descoberta atrelava-se a uma crítica de nosso conhecimento, Bergson não podia contentar-se em extrair as suas conseqüências negativas: o tempo, mesmo definido pelo decorrer, ou justamente por essa razão, não pode ser uma pura e simples desaparição, de instante em instante. Para devolver todo o seu alcance à concepção bergsoniana do tempo, é preciso então seguir o seu percurso positivo de conjunto, ao preço de reencontrar em seguida um trabalho crítico que, longe de ser uma aplicação do percurso, constitui a sua própria fonte.

As etapas da demonstração, que conduz de imediato Bergson à noção de duração, poderiam ser resumidas da seguinte maneira.

Seu decorrer contínuo conduz primeiramente a pensar um princípio de conservação do tempo. Mas o que se deduziria assim não é somente a função da consciência como memória. O que é preciso pensar, com efeito, é um modo de conservação do tempo que não seja contraditório com a sua própria sucessão ininterrupta: dessa simples observação Bergson tira 
a noção de duração como forma, desta vez da consciência temporal, precisamente enquanto tal forma é inseparável de seu conteúdo, sendo de algum modo a sua auto-conservação e auto-estruturação. É neste sentido que a duração se oporia ao "tempo", se é preciso entender por esse termo um quadro formal e vazio, no qual ocorreriam todas as sucessões, ou ainda um ato subjetivo de síntese do sucessivo, independente da sucessão mesma. Entretanto, essa auto-estruturação de um conteúdo, como aliás a memória, supõe um ato ou antes uma atividade contínua de um sujeito, abrindo-o para o seu futuro e talvez para a sua liberdade. Assim, não somente passado, presente e futuro se unem na continuidade da duração, mas guardam nela uma significação distinta, e constituem o passado, o presente e o futuro de alguém, a realidade do tempo sendo inseparável não tanto de um "sujeito" abstrato, psicológico ou "transcendental", mas de um indivíduo que leva uma vida ou uma história elas mesmas temporais.

Mas voltemos rapidamente a cada uma dessas etapas.

Que o decorrer do tempo suponha uma "consciência" chama uma dupla precisão: não somente a consciência não é dada, ao mesmo título que o tempo, e de algum modo se encontra precedida, para o filósofo, por seus próprios "dados imediatos", mas a lição que ele tira não concerne tanto a uma "doação" do tempo "a" uma consciência quanto a umaestruturação interna da consciência temporal, que fará dela propriamente uma "duração".

Contra toda tentativa de fazer do tempo um objeto proposto ao nosso conhecimento ou mesmo construído por ele, tal como a tentativa evolucionista esquematizada por Guyau em sua Genèsede l'idée de temps, Bergson evocará esse lado primitivo do ser do tempo em relação ao nosso conhecimento: "Perguntar-se por qual processo nós chegamos a conhecer um objeto é supor tal objeto invariável, e de alguma forma exterior à consciência. Mas tal suposição torna-se contraditória assim que se trata da duração, cuja essência é decorrer sem cessar e só existir, por conseqüência, para uma consciência e uma memória" (BERGSON, 1972, p. 353).

Se a duração não existe portanto senão "para" uma consciência, não é no sentido de que ela apareceria "a" uma consciência que seria a sua espectadora, mas na medida em que existiria, ela própria,como consciência, esta última sendo mesmo, por seu ato ou atividade própria, sua condição efetiva de possibilidade. De fato, ao longo de toda a obra de Bergson, consciência e memória permanecerão coextensivas. Entretanto, é preciso não se enganar quanto a isso, se a consciência supõe uma 


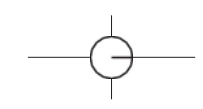

\section{4}

memória, não é diretamente aquela de que temos correntemente a experiência "psicológica". É isso que Bergson tornará mais preciso, na outra extremidade de sua obra, num texto pouco lembrado de Durée et simultanéité:

Não há dúvida de que o tempo se confunde inicialmente para nós com a continuidade de nossa vida interior. O que é tal continuidade? É a de um decorrer e de uma passagem, mas um decorrer e uma passagem que se bastam a si mesmos $<\ldots>$. Ela é memória, mas não memória pessoal, exterior ao que ela retém, distinta de um passado cuja conservação ela asseguraria; é uma memória interior à própria mudança, memória que prolonga o antes no depois e os impede de ser puros instantâneos que aparecem e desaparecem num presente que renasceria sem cessar (BERGSON, 1972, p. 97-98).

Se, então, o decorrer do tempo supõe a consciência, inversamente a consciência assim deduzida deve sua própria estrutura a esse decorrer. Para além da função da memória, é portanto efetivamente a relação entre o conteúdo e a forma do tempo que o simples fato da sua passagem deve conduzir a reconsiderar.

Assim, no Essai sur les données immédiates de la conscience, a memória está efetivamente presente na primeira definição da duração: mas está longe de ser suficiente para caracterizá-la, e passa para o segundo plano, para trás da auto-estruturação de um conteúdo sensível e temporal, que reenvia ao ato de um sujeito. É preciso citar esta passagem clássica:

A duração totalmente pura é a forma que toma a sucessão de nossos estados de consciência quando nosso eu se deixa viver, quando ele se abstém de estabelecer uma separação entre os estados presentes e os estados anteriores. < .. > Basta para tanto que, ao relembrar tais estados, ele não os justaponha ao estado atual como um ponto a outro ponto, mas os organize com ele, como acontece quando nós nos lembramos das notas de uma melodia fundidas, por assim dizer, entre si

(BERGSON, 1959, p. 67).

Assim, a duração supõe a memória; mais ainda, se podemos compará-la com uma "melodia", não é com uma melodia que estamos ouvindo no momento (como se a sensação reproduzisse em parte a descontinuidade inerente à produção física dos sons), mas sim à lembrança indivisível de uma frase musical.Todavia, o que define a duração em si mesma, mais que a memória que é sua condição, é a forma "orgânica" tomada pelo 
conteúdo do tempo, por oposição, além do mais, a uma outra forma que nossa consciência pode lhe impor, e cuja crítica parece indispensável.

De fato, é realmente aqui que alcançaríamos o percurso adotado por Bergson no capítulo central do Essai, que começava abruptamente por uma crítica do número. A numeração aparecia de imediato como o modelo de uma conservação dos momentos do tempo que abolia o seu caráter próprio, isto é, a sucessão. Longe de supor uma síntese progressiva das partes num todo, uma adição supõe o processo inverso:"para que o número $<\ldots>$ cresça à medida que eu avanço, é preciso de um modo ou de outro que eu retenha as imagens sucessivas, e que eu as justaponha a cada uma das unidades novas cuja idéia eu evoco: ora, é no espaço que uma semelhante justaposição se opera, e não na duração pura" (BERGSON, 1959, p. 53; cf.WORMS, 1994).

Seria preciso lembrar aqui o que a forma espacial impõe aos momentos do tempo, a saber, os caracteres de uma multiplicidade de partes distintas e homogêneas, consideradas num único e mesmo instante. Entretanto, o que é preciso sublinhar antes de mais nada, não é somente que Bergson define a duração através de características diretamente opostas, para nela ver uma multiplicidade indistinta e indivisível de partes heterogêneas que compõem um todo qualitativamente singular; mas sobretudo que apenas esses caracteres podem dar conta de uma conservação na e pela sucessão em si mesma. Os momentos que passam não podem se conservar como tais a não ser passando, pode-se dizer, uns nos outros. A condição paradoxal da conservação dos momentos é que sua sucessão não possa mais se pensar como uma distinção e como uma separação que a conservação deveria justamente compensar ou reparar, mas sim que a sucessão seja em si mesma uma fusão, sem o menor intervalo vazio, entre o que não é nem mesmo o passado, o presente ou o futuro. Mas o que nos prova que os momentos do tempo se fundem assim uns nos outros, que o presente não sucede ao passado, mas o prolonga e a ele se acrescenta por si mesmo, para formar um todo que é também um movimento contínuo?

O que vem prová-lo, segundo Bergson, é a uma só vez a experiência psicológica imediata, isto é, o efeito sensivel da sucessão temporal, e a mudança radical que lhe é imposta por uma simbolização espacial do tipo da numeração ou da medida, que faz da sucessão uma série de objetos distintos num espaço exterior. Assim, para tomar dois exemplos recorrentes nesse capítulo central, antes que eu os conte, os sons do sino me afetam globalmente por sua mera sucessão na minha consciência; ou 


\section{6}

ainda, depois que eu parei de "contá-los", os carneiros que não faço mais que enumerar ou desfilar em minha consciência continuarão a me afetar, embalando-me e adormecendo-me. Assim, aquilo que manifesta a interpenetração dos momentos do tempo não é o instante da sua soma, mas a imediatez do seu efeito, imanente à sua própria sucessão. $\mathrm{O}$ tempo não se representa como tal, a seco, como uma sucessão abstrata de "fases" ou períodos, mas se experimenta como conteúdo incessantemente cambiante: a continuidade desse conteúdo dá-lhe sempre uma nova forma, isto é, um novo sentido para aquele que o vive; a temporalidade e a sensibilidade são tão estritamente coextensivas quanto a memória e a consciência.

Assim, e este é um ponto essencial, as partes do tempo não se conservam num todo senão ao cessar de serem partes que aliás elas jamaisforam: só se pode pensar a sua conservação sob a condição de parar de pensá-las como partes, ou seja, no fundo, sempre como instantes. Mais exatamente ainda, as partes do tempo não são senão partes virtuais, cuja atualização por nossa reflexão transformará a sua própria natureza, já que essa atualização supõe uma justaposição no espaço, que as retira de sua sucessão imanente (a cujo mecanismo retornaremos adiante). O que é preciso então criticar é, a uma só vez, a idéia de um "tempo" homogêneo e a de um sujeito exterior que realizaria a síntese dos instantes distintos de sua vida: a sucessão é sempre uma experiência, a sucessão de algo é sempre a vida de alguém. Se a passividade do tempo vivido é ao mesmo tempo a atividade de um sujeito vivo é porque o "fato" da sucessão é ao mesmo tempo um ato "se fazendo". No "se fazendo" de Bergson, o gerúndio e o reflexivo são inseparáveis.

Será necessário, decerto, explicar como se constitui uma consciência do tempo, e no mesmo golpe um tempo homogêneo exterior à consciência: não seria esta a condição para que apareça uma verdadeira consciência, que não se reduza a um conteúdo psíquico e a uma coisa, e para que, inversamente, as coisas possam participar da temporalidade sem serem assimiladas a consciências, a sujeitos? A imanência recíproca do tempo e da consciência bem parece nutrir um realismo da consciência e um espiritualismo do real. Mas é preciso nuançar: por serem o avesso uma da outra, a duração e a consciência nem por isso se identificam, e isso graças à própria exigência da sucessão. $\mathrm{O}$ conteúdo do tempo não é uma pura "coisa", pois ele tem necessidade do ato de uma consciência para sucederse a si mesmo; mas o sujeito do tempo não é um puro espírito, pois ele deve assimilar um conteúdo que ele não pode constituir de outra forma 
senão ao vivê-lo. A sucessão une forma e conteúdo do tempo através de sua transformação comum e incessante.

Assim, a função anônima da memória não conduz somente à forma singular de uma duração individual, mas ao ato pelo qual esta se prolonga num futuro que ela cria como tal, que não lhe poderia preexistir,ainda que como horizonte, e mesmo sobretudo não como horizonte. $\mathrm{O}$ terceiro capítulo do Essai, que versa sobre a liberdade, pode legitimamente se apresentar como a simples conseqüência do capítulo precedente, mesmo se ele chama análises mais profundas da ação e da criação, assim como da vontade. É livre o ato que atualiza exclusivamente a duração da pessoa que é o seu sujeito, não aquele que visa a um fim ou "realiza" um possível ou um motivo exterior, seja ele racional ou universal, mas aquele que "decorre", por um processo contínuo, de uma intenção e de um esforço, de uma hesitação e de um progresso no tempo. Nesse sentido, apenas o ato livre abre verdadeiramente um futuro, no próprio momento em que se realiza, e jamais previamente. Todos os outros atos se mantêm no instante da representação, não produzem o novo. O paradoxo da liberdade segundo Bergson intensifica portanto a duração: é uma liberdade de um eu que não é exterior a seus atos, e não saberia se destacar deles. $\mathrm{O}$ ato livre "expressa"3 o eu, por sua significação, mas também como o suco de um "fruto muito maduro". Mas esse paradoxo do ativo e do passivo é ainda uma vez resolvido pela sucessão apenas, tornada atualização, "energia" ou ainda "progresso". Nem liberdade intemporal, nem ato instantâneo, o tempo da ação ou da atividade funda uma liberdade que é a uma só vez uma espécie de força psíquica e de esforço moral, uma relação de um efeito com um processo causal que comporta, enquanto tal, "graus".

Tal seria portanto a concepção "bergsoniana" da "duração". Ela compreende memória, duração propriamente dita, e criação ou vontade. Bastaria sem dúvida the acrescentar os processos de uma espacialização instantânea para reencontrar os aspectos do tempo ainda ignorados por ela: distinção das três dimensões do tempo, constituição do movimento e do tempo das coisas, determinação causal e historicidade. Mas antes de ver tais dimensões introduzirem-se no processo temporal pela mesma janela, a do instante, é preciso mostrar como a análise da própria duração ainda não está completa, longe disso. Contrariamente àquilo em que se poderia acreditar, a memória de Matièreet Mémoire, a criação de L'Évolution Créatrice não estão analiticamente contidas na duração do Essai sur les données immédiates de la conscience, mas, sem a contradizer, irão aprofundá- 


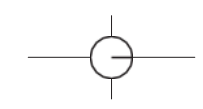

\section{8}

la e renová-la em seu conjunto. É preciso dizer uma palavra sobre essas duas surpresas, cada uma das quais estará no centro de um novo livro de Bergson, antes de mostrar como, à duração da consciência, opõe-se o pensamento do instante.

Um primeiro erro consistiria com efeito em colocar Matière et Mémoire numa continuidade direta com o Essai de 1889. Certamente, a teoria de uma conservação integral de nosso passado numa memória "pura" parece vir completar a teoria de uma auto-estruturação da passagem temporal como duração. Mas, na verdade, ela obriga sobretudo a aprofundar esta última. O que Matièreet Mémoire renova, bem mais que a teoria da memória pura, é antes de mais nada a significação da duração presente como "memória imediata". É a passagem que permanece primeira, sem que se possa considerar (como havia feito Cassirer, por exemplo) que o tempo bergsoniano se caracteriza antes de tudo pelo peso do "passado". Para compreendê-lo é preciso transportar-se de imediato para o centro do livro de 1896, centro que é novamente apresentado por Bergson como origem da obra: não é por acaso que a "intuição" de partida, que versa ainda sobre o próprio decorrer do tempo, se vê remetida ao coração dos desenvolvimentos teóricos que ela tornou possível e que, em contrapartida, a verificam.

Bergson não somente descreveu uma auto-conservação do passado, numa memória pura, indistinta e integral, "coextensiva à nossa consciência": ele opôs, a essa memória própria ao passado, uma memória "do corpo","quase instantânea", constituída por repetição e hábito.A questão para ele é portanto religá-las. Ora, essa ligação não seria possível se, entre a memória do passado e os mecanismos do corpo, não se intercalasse uma terceira memória, que é a memória essencial, aquela que define nossa própria consciência imediata: "Mas se nunca percebemos outra coisa senão nosso passado imediato, se nossa consciência do presente é já memória, os dois termos que havíamos separado vão se soldar intimamente entre si”(BERGSON, 1959, p. 292; grifo meu).

Entre dois limites, o de uma "percepção pura" instantânea até na sua memória-hábito e o de uma memória integral do passado, existe a consciência concreta: coextensiva ao presente do corpo, ela é também consciência do passado e pode explorar a memória pura; mas o que torna possível essas duas funções fundamentais é a sua própria estruturação interna, como síntese do "passado imediato" e do "futuro iminente". Tal é o sentido do esquema dito do "cône" em torno do qual se dispõe o conjunto da teoria, ao mesmo tempo psicológica e metafísica, de Matièreet Mémoire. 
Assim, a duração toma realmente o sentido de uma verdadeira memória, permitindo ao conteúdo do passado inscrever-se na atividade temporal do sujeito, por uma atualização real. A memória bergsoniana é atualização antes de ser reminiscência. Inversamente, ao inscrever-se na consciência imediata, o passado do indivíduo dá a essa última a profundidade de uma história pessoal que enriquece os seus atos e o sentido de sua liberdade. Todas essas análises supõem entretanto, antes de mais nada, o aprofundamento da própria consciência imediata, definida então por Bergson como "contração de instantes".

É preciso ir mais longe: esta consciência imediata e esta duração têm agora um estatuto ontológico singular para além da "passagem" do tempo em geral. Cada tipo de consciência opera a contração de instantes que a define como tal, segundo um "ritmo" que a situa por analogia numa escala intensiva, e sempre temporal, de realidade. Nossa duração estaria situada, dessa forma, entre a consciência mínima do universo material (mínima porém irredutível a uma pura espacialidade instantânea) e uma possível supra-consciência capaz de contrair na sua tensão uma duração maior que a nossa.A própria independência da matéria em relação a nós se manifestaria na irredutibilidade de sua temporalidade à nossa (irredutibilidade que o "copo de água com açúcar" logo manifestará), enquanto que nossa percepção toma o sentido de uma intersecção imanente entre dois ritmos de duração heterogêneos e contemporâneos. A distinção entre durações, longe de excluir sua participação, a implica: sem se confundirem, as durações, isto é, as realidades individuais, podem se conhecer mutuamente, só podem mesmo se conhecer do interior. Se o instante da percepção as separa numa pura diferença, ele também une duas temporalidades numa imanência comum.

Há então um segundo erro a evitar: aquele que consiste em acreditar que Bergson não tinha senão que situar "a vida" nessa escala temporal de realidade para escrever L'Évolution Créatrice,revelando mesmo a natureza profunda de sua filosofia como "filosofia da vida".

De fato, a obra de 1907 realmente começa situando a duração que o ser vivo deve à vida entre a duração de cada consciência e a do universo material: "Como o universo em seu conjunto, como cada ser consciente tomado a parte, o organismo que vive é algo que dura"(BERGSON, 1959, p. 507).

Mas esta descrição inicial da duração consciente não tinha consistido somente, apesar da declaração de Bergson, em retomar "as conclusões de um trabalho anterior”(1959, p. 495). Reencontrando as características 


\section{0}

fundamentais da duração, Bergson insistia com efeito na criação imprevisível que ali se dá, a ponto de fazer dela o seu traço distintivo. É que aí também havia sido necessário um novo aprofundamento do ponto de partida inicial; aí também este havia tido lugar no coração do livro, em seu terceiro capítulo sobre "a significação da vida". Longe de ser uma "filosofia da vida" se entendemos por isso uma filosofia para a qual a vida é o princípio primeiro ao qual tudo deve ser reconduzido, a doutrina de Bergson faz a compreensão desta última depender de um aspecto ainda insuficientemente aprofundado do tempo e da consciência, da própria duração.

Bergson foi, com efeito, conduzido por seu estudo da evolução da vida a compreender esta última como "criadora": a diversidade do ser vivo reenvia segundo ele a uma finalidade original, não como a uma intenção inteligente, mas como à atualização de potências contidas numa totalidade indivisível, um "elã" inicial. Mas isso não é suficiente: é preciso mostrar como, inversamente, a criação pode ser pensada não como a realização de um plano, ou a cópia de um modelo, mas como a simples atualização temporal de potências indistintas, como uma pura e simples "evolução". É portanto para dar um fundamento à teoria da evolução que Bergson é reconduzido à própria duração psicológica, e daí a uma teoria geral da criação: a criação biológica propriamente dita tomará seu lugar entre o ato livre de uma consciência singular e aquilo que se torna a criação do universo material ele mesmo (atingido em uma frase enigmática que fez correr muita tinta). Mas a resposta deve novamente ser procurada na duração mesma, isto é, mais uma vez e com extremo rigor, no decorrer do tempo, Bergson nos surpreendendo cada vez mais pela distância entre a exigüidade do ponto de partida e a amplidão de suas conseqüências.

É então o próprio esforço para remontar à duração que revela a sua essência ativa, como criação de um futuro: "é preciso que, por uma contração violenta de nossa personalidade sobre si mesma, nós reunamos nosso passado que se esquiva, para impulsioná-lo, compacto e indiviso, num presente que ele criará ao nele se introduzir"(BERGSON, 1959, p. 665). Ou ainda: "Quanto mais nós tomamos consciência de nosso progresso na pura duração, mais nós sentimos as diversas partes de nosso ser entrarem umas nas outras e nossa personalidade inteira concentrar-se num ponto, ou melhor, numa ponta, que se insere no futuro encetando-o sem cessar"(BERGSON, 1959, p. 666).

A esse movimento, opõe-se agora, no instante de sua interrupção,o movimento inverso que dá uma forma a tal esforço: forma de um ato ou de um 
estado de consciência dado, em nossa consciência, por exemplo.A consciência ativa do tempo torna-se então ela mesma produtora ou criadora de um efeito. Ora, segundo Bergson, a vida não faz nada além, ela também, do que inserir a temporalidade numa matéria, e criar assim, num instante que é um limite ou uma parada, a cada vez uma nova espécie. O que toma um novo alcance é portanto a idéia de uma criação e de uma ação imanente ao tempo e ao próprio devir, cujo "resultado" se destaca simplesmente como seu termo contingente, bem mais do que como um fim concebido desde o início enquanto tal. Assim, não somente o tempo é ação, mas ele é criação, não somente ele introduz num futuro indeterminado, mas é o sentido de suas três dimensões que se transforma profundamente: a indeterminação do futuro faz do presente uma novidade, tal como faz aliás do passado, por um efeito retrospectivo fundamental, uma possibilidade.

Não é, portanto, somente "o futuro" da criação que se acrescentaria aqui, de maneira sistemática, às outras dimensões do tempo, para completar o estudo da "duração": o movimento contínuo da passagem, do devir de cada realidade singular permanece primeiro e fundamental, através de suas mutações sucessivas.

Assim, a "concepção bergsoniana" do tempo, sem mudar de princípio original, não pára de revelar nele novos aspectos. O presente contínuo da consciência desdobra-se por si mesmo em memória e em vontade, em passado e em futuro. Falta ainda compreender como essa concepção só pode ser completada ao se acrescentar um trabalho crítico, ele próprio a cada vez renovado. Mas, assim como a duração da consciência, ou o decorrer do tempo, permanece o princípio de toda concepção bergsoniana do tempo, através de suas múltiplas transformações, do mesmo modo, sem procurar apurar os múltiplos tópicos que ela reencontra - argumentos de Zenão, crítica da metafísica, da percepção, da linguagem - nós não faremos senão indicar o princípio central da crítica de Bergson, a saber, não tanto o espaço enquanto tal, mas o limite paradoxal que ele compartilha com a duração, o pensamento do instante que ele implica sempre. É apenas esse pensamento que é preciso tentar seguir agora.

\section{Do pensamento do instante à experiência da simultaneidade}

Não se trata simplesmente para Bergson de "completar" sua doutrina da duração por uma crítica do espaço, para denunciar a ilusão de um "tempo" homogêneo e exterior a seu conteúdo, assim como para dar 


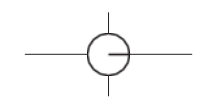

\section{2}

conta do lugar dessa ilusão em nossa experiência cotidiana. Não se trata para ele de resolver a priori aquilo que Paul Ricoeur denomina "aporética do tempo" (1983), entre o tempo da consciência e o tempo das coisas, a "distentio animi" herdada de Santo Agostinho, e o tempo "físico" de Aristóteles, opondo-os como a parte do real e a do imaginário de nossa experiência do tempo em geral. Se há espacialização da duração, e temporalização do espaço, não se trata aí somente de contradições teóricas (a superar numa síntese dos contrários), mas bem antes de realidades primitivas (que foi preciso começar por analisar e dissociar).

De fato, o espaço não é apenas um princípio formal e exterior: é uma "intuição" ou um pensamento, que tem por característica dar-se de direito em um puro instante. Se esse instante deve ser primeiro criticado, é do interior: é através dele que nossa experiência do tempo se desdobra constantemente em um fluxo contínuo e em cortes estáticos, em progresso e em coisas, em movimentos e em imagens. Entretanto, desde o Essai sur les donées immédiates de la conscience,o instante não é somente a condição de um pensamento abstrato do espaço: é também o modo de relação com o espaço concreto das coisas, através da sua sensação ou mais exatamente da sua percepção, esta mesma percepção que o primeiro capítulo de Matièreet Mémoire descreverá ou deduzirá como "percepção pura" (precisamente porque aí se fez abstração da duração). $\mathrm{O}$ instante não é então somente um limite abstrato do tempo, é uma relação entre o espaço e o tempo, e uma relação instantânea ou antes a instantaneidade como relação deve chamar-se simultaneidade.

Essa relação não cessará de reaparecer no coração de cada um dos grandes livros de Bergson até Duréeet Simultaneité, em 1922, e mesmo além. Assim, o tempo de Bergson não se reduzirá a uma "distentio animi", se o instante não se reduz ao limite do movimento, e é sem dúvida no encontro entre Bergson e Einstein que se reencontra, no ponto mais extremo do pensamento moderno, o "debate" entre Santo Agostinho e Aristóteles. Se devêssemos nos limitar a constatar seu mal-entendido, deveríamos ver aí, com Merleau-Ponty, o indício mais sério de uma "crise da razão"; mas se, como o próprio Merleau-Ponty pôde mostrar, pudéssemos aí experimentar uma dualidade irredutível e portanto original, seríamos então reconduzidos, de uma vez, para além de toda redução simplista, ao "misto" que é a experiência humana do tempo, sob todos os aspectos.

Sem poder dar conta do conjunto do percurso crítico de Bergson, é então para esse único ponto que nos dirigiremos aqui.Assim, no próprio Essai sur les donées immédiates de la conscience, já se unem os aspectos críti- 
cos e mediadores do instante e da simultaneidade: o instante não é somente o princípio do espaço e da espacialização ilegítima do tempo, mas o princípio da sensação das coisas, da relação com elas tanto quanto da distância a si.

Quanto ao primeiro capítulo de Matière et Mémoire, ele exigiria aqui um estudo dos mais atentos. Ele constrói a hipótese, efetivamente, com base apenas na ação do corpo, de uma percepção objetiva pura e instantânea, revelando assim a causa e o efeito da própria espacialização. Sua causa: a necessidade da ação que nos oculta a realidade do tempo. Mas sobretudo seu efeito: ela constitui um mundo de objetos ou de imagens, separados do sujeito por uma distância espacial pura, que é também uma relação "intencional" exteriorizada. Os objetos se dão como distância ao corpo, num horizonte e até num horizonte de horizontes, que é o horizonte da ação. Este primeiro capítulo não tem portanto nada de uma "fenomenologia" pura, que antes prejudicou a sua leitura: ou melhor, ele apóia toda fenomenologia sobre a disposição espacial que nossa ação impõe a todo instante ao nosso pensamento.Ao ultrapassá-la, não se teria mais acesso a uma distância, mesmo intencional, a algum "conteúdo" qualquer que seja: reencontrar-se-ia a imanência propriamente metafísica da duração. É verdade que, em contrapartida, ao fazer do espaço ele próprio o princípio puro de nossa relação com o objeto, pode ser que Bergson exteriorize e naturalize a intencionalidade da consciência. Mas este é um outro debate.

É portanto efetivamente o instante que permaneceria o princípio de uma relação com as coisas: é através da ponta do corpo percipiente, a cada instante de nossa vida, que a duração se inscreve no mundo. Nosso pensamento corre assim o risco de ocultar-se sua realidade temporal e a da matéria, ao interpor entre elas um espaço de objetos. Mas é também ao superar essa mediação que ele pode voltar ao contato entre as duas durações, a reflexão crítica sendo aquilo que dá à intuição imediata o sentido de uma intuição filosófica, que deve não tanto ultrapassar, mas sim reencontrar a primeira, para além dos obstáculos da consciência objetiva.

É enfim através do "mecanismo cinematográfico" de nosso pensamento que Bergson, em L'Évolution Créatrice, leva ao limite a crítica do instante. Resumamos simplesmente os seus dois tópicos principais.

Para começar, em lugar de devires singulares e sempre cambiantes, nosso pensamento é conduzido pela estrutura que ele mesmo deve à vida a ali recortar instantes, e sobretudo a construir a oposição entre, de um lado, instantes plenos de conteúdos e sentidos congelados em formas fixas, 


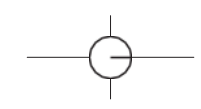

\section{4}

e, de outro, um devir em geral, vazio e puramente negativo. Tais são as imagens da película, animadas pelo movimento vazio do motor de um projetor. Assim, o falso problema do devir seria (do Parmênides de Platão à Lógica de Hegel, pode-se dizer) o de reunir o ser imutável e o nada da pura mudança, enquanto que um e outro são dados num devir a cada vez singular, de onde eles foram abstraídos por nosso pensamento. Compreende-se por que Deleuze viu (nas etapas de transição de Cinema 1 e 2), não no "mecanismo" do cinema, mas em certos filmes, que superam precisamente o espetáculo de imagens sem movimento nem tempo interno, o meio de reencontrar o devir imanente da duração bergsoniana ela mesma.

Esta crítica radical do instante acrescenta, portanto, à célebre crítica da idéia do nada, uma crítica menos conhecida da idéia de ser ou de essência, através da noção de forma. Mais ainda, de maneira constitutiva, a crítica toma uma forma histórica. O pensamento grego teria assim encontrado o ser no instante:"nós poderíamos e mesmo deveríamos traduzir eïdos por 'vista', ou antes por 'momento'”(BERGSON, 1959, p. 761; cf. NARCY, 1997).

A ciência moderna representa então um compromisso: "a ciência antiga acredita conhecer suficientemente seu objeto quando ela anotou dele momentos privilegiados, ao passo que a ciência moderna o considera em todo e qualquer momento"(BERGSON, 1959, p. 774).

Mas se o instante qualquer já permite devolver ao próprio tempo uma certa positividade, ele ainda não permite compreender a sua atividade interna. A física moderna "repousa totalmente sobre a substituição do tempo invenção pelo tempo-comprimento"; ora, "ou o tempo é invenção ou não é absolutamente nada"(BERGSON, 1959, p. 784).

Seria portanto somente levando ao seu limite a crítica do instante que se alcançaria no mesmo golpe a concepção completa da duração como criação, do devir como "devir real", no duplo sentido que essa expressão pode ter (quer se substantive o infinitivo, quer se o recoloque em movimento). A respeito disso, a seção sobre o "devir e a forma" constitui um dos ápices inexplorados de toda a obra de Bergson.

Mas é preciso ir mais longe. Somente a retomada direta da noção de simultaneidade, à qual a física de Einstein obriga Bergson, pode fazer aparecer a solidariedade íntima entre o pensamento do instante e o presente da consciência, ao ponto de fazer deles duas faces de uma mesma experiência da duração. É preciso portanto dizer uma palavra sobre esse tópico, para retornar em seguida à passagem ou ao próprio 
decorrer do tempo, e saber se esse ponto de partida foi não apenas respeitado como tal, mas também esclarecido, em contrapartida, pelos desenvolvimentos aos quais ele deu lugar.

No Essai sur les données immédiates de la conscience, a simultaneidade já aparece como uma pura relação entre duas realidades, cuja natureza ela pressupunha entretanto conhecida:

Há um espaço real, sem duração, mas no qual fenômenos aparecem e desaparecem simultaneamente com nossos estados de consciência. Há uma duração real, cujos momentos heterogêneos se penetram, mas da qual cada momento pode ser aproximado de um estado do mundo exterior que lhe é contemporâneo, e se separar dos outros momentos pelo próprio efeito dessa aproximação. $<\ldots$... e o traço de união entre esses dois termos, espaço e duração, é a simultaneidade, que se poderia definir como a intersecção do tempo com o espaço"

(BERGSON, 1959, p. 73-74).

Puro traço de união capaz de engendrar, por repetição e hábito, assim como por mistura imaginária, todos os mistos de nossa experiência, a simultaneidade não afeta entretanto em profundidade a realidade dos termos que ela religa. Ora, tudo se passa como se, por sua própria passagem ao limite, Einstein obrigasse Bergson a ir mais longe.

Com efeito, Bergson vê na teoria da relatividade de Einstein um esforço para fazer da simultaneidade não um dado subjetivo ou imediato, mas uma pura relação objetiva e variável, entre coisas ou eventos que a velocidade da luz impede de situar num mesmo instante. Ora, segundo Bergson, Einstein realiza assim o trabalho da física moderna, ao dissolver o instante da coisa numa pura simultaneidade entre eventos. Com Einstein se realiza a visão cartesiana do universo, como universo de "relações", que não têm aliás nada de "relativo" no sentido subjetivo do termo, uma vez que elas revelam a estrutura matemática autêntica do universo real. Einstein acrescenta portanto um episódio ao último capítulo de L'Évolution Créatrice.

$\mathrm{O}$ que Bergson contesta não é portanto a pertinência física desse esforço teórico, mas sim que a simultaneidade assim descrita possa ser a da nossa experiência temporal. Não se trata aí de opor um tempo "físico" a um tempo "psicológico", mas bem antes de mostrar que nenhum do dois jamais se dá puro em nossa experiência, ou ainda que nossa experiência situa-se sempre na intersecção dos dois, através da percepção. Ora, desde que ele é percebido, o tempo físico reintegra uma simultaneidade 


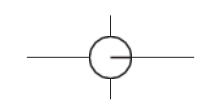

\section{6}

absoluta, a que religa não coisas entre si, mas coisas e uma consciência, através do instante de um olhar. O que obriga a operar essa reintegração não é então um desejo de "salvar" a duração, é a exigência de preservar a unidade da experiência. É porque o universo não pode existir sem ser percebido, segundo o princípio que Bergson toma de empréstimo a Berkeley, que ele não pode ser espaço-temporal sem estar ao mesmo tempo no cruzamento de um corpo e de uma consciência ${ }^{4}$.

Se uma simultaneidade puramente objetiva não poderia ser percebida enquanto tal, uma pura duração, sem simultaneidade (pela percepção e pelo pensamento) com o universo, não o poderia também.

Merleau-Ponty resumirá perfeitamente esse duplo deslocamento, necessário para conciliar Einstein e Bergson sem sacrificar as exigências nem de um nem de outro, uma vez que cada uma delas corresponde com efeito a uma dimensão de nossa experiência mesma: "Somente coisas percebidas podem participar da mesma linha de presente - em contrapartida, desde que haja percepção, há imediatamente e sem restrições simultaneidade de simples visão, não somente entre dois eventos do mesmo campo, mas mesmo entre todos os campos perceptivos, todos os observadores, todas as durações" (MERLEAU-PONTY, 1960, p. 233-234)5.

Assim se juntam todas as dimensões do instante, ou antes da simultaneidade sempre recomeçada que define nossa experiência: corte que desdobra sempre nosso devir, janela por onde nossa percepção se abre para o mundo, possibilidade oferecida à ação e ao conhecimento, sob o risco de se perder mas também de se recobrar. Experiência sempre simultânea ou reversível, entre a duração e o pensamento, uma relação consigo e com o mundo, que não é jamais condenada a se desdobrar, mas cuja coincidência, muito embora seja deduzida pelo filósofo, não é jamais garantida a nenhum de nós, no curso mesmo de nossas vidas.

\section{Conclusões}

Um sistema que, como o de Bergson, exprime e desenvolve uma intuição simples e coerente, pode pretender ser medido segundo seus próprios critérios, e não examinado e julgado de fora. Por conseqüência, nós lhe perguntaremos, unicamente, se ele permaneceu fiel à sua própria tarefa e à sua própria norma, e se ele realmente apreendeu e descreveu como um todo o fenômeno do tempo tal como ele se representa na intuição pura. 
Assim Ernst Cassirer expressava, em Philosophie des formes symboliques (1972, p. 212), a exigência mesma na qual as observações precedentes tentaram se inspirar. É verdade que seria necessário também, para fazê-lo, levar em conta, entre outros, o próprio exame de Cassirer, e notadamente a contraposição por ele esboçada entre a doutrina de Bergson e a de Heidegger. Com o autor de Sere Tempo, ele no fundo reprova em Bergson o seu realismo, herdeiro de uma filosofia da vida, e um desconhecimento da abertura temporal para um "possível" irredutível a uma indeterminação ou a uma criação. Aqui não é o lugar para entrar numa tal confrontação, nem em nenhuma outra. É preciso somente tentar reunir os resultados de nosso rápido percurso, para ver se acaso nele se esboça uma resposta ao tão poucas vezes enfrentado desafio de Cassirer, e se não haveria aí uma tarefa importante a conduzir para pensar a experiência temporal, nossa experiência do tempo, ainda hoje.

Nós sublinharemos apenas três pontos a esse respeito.

Para começar, parece com efeito que o conjunto da filosofia de Bergson tenha permanecido fiel ao seu ponto de partida, a saber, o decorrer que define o tempo como tal. Seu aprofundamento permitiu alcançar, sem ultrapassar esse ponto de partida, a uma só vez as dimensões internas do tempo e tudo o que parece contradizê-lo. Longe de se resumir a uma "psicologia", a obra de Bergson não cessa de desenvolver a metafísica e a teoria do conhecimento que seu duplo ponto de partida, no Essai sur les données immédiates de la conscience, já pressupunha sem as conter. Tudo se reporta portanto, no fundo, ao duplo sentido do presente, como duração e como instante.

Em si, o presente não existe: "a intuição de que falamos versa fundamentalmente sobre a duração interior. Ela apreende uma sucessão que não é justaposição, um crescimento por dentro, o prolongamento ininterrupto do passado num presente que invade o futuro"(BERGSON, 1959, p. 1272-1273).

Mas o instante fixa esse devir em presença e me dá de uma vez toda a objetividade, por uma fiç̧ão que é também um fundamento, e uma pura relação. Enfim, e talvez sobretudo, o instante do pensamento é a própria condição do pensamento da duração, isto é, da intuição do presente como não-instantâneo. A consciência, numa intuição filosófica que é "também reflexão", pode enfim ver o que ela vive, ou antes, não faz senão ver o que ela já vivia, pode "ver o tempo passar".

Mas, justamente, "ver o tempo passar" não é a expressão do tédio ou da lassidão diante da repetição do mesmo. É ao contrário uma surpresa 


\section{8}

sempre renovada, diante de uma mudança temporal, e mesmo de uma criação continuada de sentido e do desconhecimento que nos separa dela. Assim se explica o esforço de cada um dos livros de Bergson, que define mesmo cada um dos livros de Bergson. A chave última talvez seja fornecida por Les deux sources de la morale et de la religion, se é verdade que o esforço e o obstáculo que o filósofo encontra são vividos pelo grande homem de bem e pelo místico como uma prova histórica, mais rica ainda de verdade metafísica, e que o filósofo não pode mais interpretar a não ser do exterior.A "alegria" tematizada em cada um dos textos de Bergson sobre o tempo desde L'Évolution Créatrice reencontra-se superabundante numa experiência mística que ela basta mesmo para definir. Esta permanece aliás vinculada (de novo no capítulo central desse último livro, aliás) à experiência da duração: ao fazer a consciência humana participar de uma duração que seria ainda mais aberta e ativa do que a sua, sem por causa disso se abolir ou se fundir nela, essa alegria arrancaria a história à repetição do mesmo ou ao simples progresso técnico, para recolocá-la no caminho metafísico que cada um de nós experimenta já em seus atos livres.

Assim, tanto quanto a "experiência do tempo", teríamos talvez alcançado, até no seu método e na composição de seus livros, a filosofia "de Bergson", como se ambas se esclarecessem reciprocamente, sem poder se resumir a alguma fórmula simples qualquer que seja.

Pode-se então compreender como essa concepção do tempo não pode reduzir-se a um realismo da duração, a uma crítica da inteligência, a um espiritualismo, mesmo se tudo isso nela se encontra de fato. Não somente essa filosofia une os contrários, como bem o viram por exemplo Deleuze ou Merleau-Ponty (sob o nome da imanência ou da diferença, da intuição ou da reflexão), como eles próprios tentaram fazer, mas ela o faz sempre voltando ao fenômeno originário que é para ela a passagem do tempo.

Talvez ela nos revele assim a sua natureza dupla e única: não contemplamos a passagem do tempo, surpreendemo-nos com ela, exclamamonos:"como o tempo passa!", "como eu mudei!". Apercebemo-nos de que alguma coisa se passou.A surpresa diante do tempo combina a realidade de uma mudança e a idealidade de um espanto, e baliza assim duplamente o curso de uma vida e a experiência de um pensamento, vida e pensamento de cada um de nós. Cada surpresa profunda rompe e reata o curso do tempo, por meio de um instante meditativo que revela uma continuidade real. Em seguida virá o relato, a questão: o que se passou, o que eu fiz, 
quem sou? Mas entre o realismo da duração e o idealismo do relato, a cada vez é oferecida a possibilidade de se relacionar consigo e com o mundo sem por isso se perder nele nem com ele se confundir.Ao passar, o tempo nos religa a nós mesmos, e a uma experiência compartilhada, que se trata menos de constituir ou de construir, do que evitar perder ou deixar destruir.

1 "La conception bergsonienne du temps", publicado em Philosophie, n54,p.73-91.Tradução de Débora Morato Pinto.

2 Todas as nossas referências reenviam ao volume das Oeuvres de Bergson, editado por Andre Robinet com uma Introdução de Henri Gouhier, ed. PUF, 1959, e, para os textos que ali não se encontram, o volume de Mélanges, sob a autoridade dos mesmos editores, PUF, 1972.

3 [NT:] O autor explora aqui os dois sentidos do verbo "exprimer": expressar e espremer (daí a metáfora do fruto).

${ }^{4}$ Sobre todos estes pontos, além de Duréeet Simultanéité, podemos remeter à nota de La pensée et le mouvant (BERGSON, 1959, p.1280-1283; cf. SOULEZ \& WORMS, 1997, cap. IX).

5 No mesmo volume, ver sobretudo, o ensaio intitulado "Einstein e a crise da razão".

\section{Referências bibliográficas}

BERGSON, H. Oeuvres (éd. du Centenaire). Paris: PUF, 1959. . Mélanges,Paris: PUF, 1972.

CASSIRER, E. Philosophie des formes symboliques - III. Paris: Éditions de Minuit, 1972.

RICOEUR, P. Temps et récit - III. Paris: Éditions du Seuil, 1983.

MERLEAU-PONTY, M. “Bergson se faisant”. In: Signes. Paris :

Gallimard, 1960.

WORMS, F. “Les trois dimensions de la question de 1'espace dans 1'oeuvre de Bergson”. In: Epokhê, n²4, 1994.

NARCY, M. “'Le principe c'est la répresentation'. Bergson traducteur d'Aristote". In: Philosophie, 54, 1997.

SOULEZ, P. e WORMS, F. Bergson, biographie.Paris: Flammarion, 1997. 